\title{
Análise dos indicadores de qualidade da água no trecho urbano do Rio Apodi-Mossoró em Mossoró-RN, Brasil
}

\author{
Water quality indexes in the urban stretch of the River Apodi- \\ Mossoró in Mossoró RN Brazil
}

\author{
Joel Medeiros Bezerra ${ }^{1}$; Paulo Cesar Moura da Silva ${ }^{2}$; Rafael Oliveira Batista ${ }^{2}$; \\ Carlos Henrique Catunda Pinto ${ }^{3}$; Alex Pinheiro Feitosa ${ }^{4}$
}

\begin{abstract}
Resumo
A água é um recurso natural fundamental para a vida, sendo indispensável em praticamente todas as atividades antrópicas. Sendo um recurso natural limitado, a preocupação com a conservação da qualidade da água tornou-se crescente, concomitante a procura de mecanismos eficazes, capazes de mitigar os impactos ambientais negativos. O presente trabalho tem como objetivo aplicar o Índice de Qualidade de Água (IQA) aos barramentos hidráulicos situados no trecho urbano do município de Mossoró-RN, sendo, posteriormente, feita a verificação da condição do corpo hídrico de acordo com as classes de uso, ressaltando os preponderantes, além da classificação prévia do corpo hídrico. As coletas de água para análise dos parâmetros referentes ao IQA foram realizadas no mês de julho de 2010, distribuídas em três barramentos situados no trecho urbano, sendo georreferenciadas, subsidiando a indicação dos pontos críticos. Foram elencadas as possíveis atividades exploratórias contribuintes com a contaminação do corpo hídrico. Por fim realizada a avaliação individual dos valores obtidos comparados com as diretrizes das legislações vigentes. Com os resultados obtidos, baseado na resolução CONAMA n ${ }^{\circ} 357 / 2005$, verificou-se que as análises para o período de estiagem, evidenciam a condição do corpo hídrico quanto a salinidade como água salobra, em relação aos usos preponderantes, Classe 1. Entretanto, quando analisados individualmente os parâmetros e comparados aos padrões estabelecidos pela resolução CONAMA n ${ }^{\circ} 357 / 2005$, constata-se que o fósforo total apresentou valores em desacordo. A partir da entrada da cidade e à jusante desta, em função da grande carga de efluentes domésticos e despejos agroindustriais, além do escoamento superficial, a água apresenta-se com qualidade boa no primeiro barramento e regular nos demais.
\end{abstract}

Palavras-chave: Corpo hídrico, poluição antrópica, gestão ambiental

\begin{abstract}
Water is a basic natural resource for the maintenance of life and is indispensable in all human activities. Since it is a limited natural resource, concern on the conservation of its quality is high, coupled with efficacious mechanisms that may diminish negative environmental impacts. Current analysis applies the Water Quality Index (WQI) for hydraulic barriers in the urban stretch of Mossoró RN Brazil and verifies
\end{abstract}

${ }^{1}$ Eng $^{\mathrm{o}}$ Agrícola e Ambiental, Discente do Curso de Doutorado em Engenharia Agrícola, da Universidade Federal Rural de Campina Grande, UFCG, Campina Grande, PB. E-mail: joel_medeiors@msn.com

${ }^{2}$ Eng $^{\text {os }}$ Agr $^{\text {os }}$, Profs. Adjunto, Universidade Federal Rural do Semi-Árido, UFERSA, Mossoró, RN. E-mail: paulo.moura@ufersa. edu.br; rafaelbatista@ufersa.edu.br

${ }^{3}$ Eng $^{\circ}$ Químico, Prof. Adjunto, Universidade do Estado do Rio Grande do Norte, UERN, Mossoró, RN. E-mail: carloscatunda@ uern.br

${ }^{4}$ Eng $^{\circ}$ Agrícola e Ambiental, Discente do Curso de Doutorado em Manejo de Solo e Água, Universidade Federal Rural do SemiÁrido, UFERSA, Mossoró, RN. E-mail: alexrn44@hotmail.com

* Autor para correspondência 
the water body conditions according to usage classes, with special reference to predominant factors and previous classification of the water body. Collection of water for analysis of WQI parameters was undertaken in July 2010 in three barriers within the urban stretch and geo-referenced for the indication of critical sites. Possible exploratory activities linked to the contamination of the water body were listed. An evaluation of rates was undertaken and compared with current legislation guidelines. According to CONAMA n. 357/2005, results showed that analyses during the dry period referred to the salinity of the water body when related to preponderant usage indexes, or Class 1 . Total phosphorus failed to comply with rates when parameters were analyzed one by one and compared to standards established by CONAMA n. 357/2005. Water was of good quality at the first barrier and fair in the others from the entrance of the city and downstream, due to the great load of home effluents, agro-industrial wastes and surface runoff.

Key words: Water body, pollution by humans, environmental management

\section{Introdução}

A água é um recurso natural indispensável para a vida, onde se evidencia a dependência por este recurso cada vez maior em praticamente todas as atividades (ATHAYDE JÚNIOR et al., 2008). Além disso, de acordo com Umetsu et al. (2012) o meio ambiente é extremamente dependente e vulnerável a alterações das condições hidrológicas. Entretanto, como consequências do grande aumento demográfico mundial, notam-se impactos ambientais negativos em função da degradação dos recursos naturais e do acúmulo de resíduos, evidenciando-se ameaças quanto à sustentabilidade da vida humana, comprometendo os recursos naturais por meio da poluição (de forma pontual e, ou, difusa) dos mesmos.

De acordo com a Política Nacional do Meio Ambiente estabelecida na Lei 6.938/1981 (BRASIL, 1981) a poluição das águas é conceituada como qualquer adição de matéria ou energia que, direta ou indiretamente, promova a alteração adversa das características naturais das águas de modo a limitar os usos previstos para mesma.

Diante desta situação, o interesse em evitar ou reduzir ao máximo as transformações ambientais se desenvolveu paralelamente com o receio de não se ter disponível, em um futuro próximo, os recursos necessários para as atividades antropogênicas. Assim, apesar de ser um bem natural limitado indispensável à vida de todos os seres vivos, a preocupação com a conservação da qualidade da água existente e dos mananciais, tornou-se maior recentemente, concomitante a procura de mecanismos eficazes, capazes de reduzir e mitigar os impactos ambientais negativos, sendo estes impulsionados pela crescente necessidade de novas fontes de disponibilidade hídrica compatíveis a tais demandas, aliada a pressão de uso imposta pelo crescimento demográfico, aumento das áreas incorporadas a agricultura e as demandas de complexos industriais e agroindustriais (ABRAHÃO, 2006; BONNET; FERREIRA; LOBO, 2008; SILVA et al., 2009; GOMES et al., 2012; OLIVEIRA et al., 2012; UMETSU et al., 2012). Desta forma, tornando indissociáveis os aspectos de qualidade e quantidade deste recurso aos seus usos múltiplos.

Visando balizar os usos múltiplos dos recursos hídricos, uma importante medida ambiental para diagnosticar um corpo hídrico é o uso de indicadores físicos, químicos e biológicos, os quais são usados para descrever e controlar as condições do ambiente aquático. O Índice de Qualidade da Água (IQA) desenvolvido pela National Sanitation Foundation (Fundação Nacional de Saúde dos Estados Unidos - NSF) com auxílio de especialistas, abrange as interações entre as diversas variáveis mensuradas em amostras de água (BONNET; FERREIRA; LOBO, 2008; SÃO PAULO, 2008). O índice propõe dar uma ideia da tendência de evolução da qualidade ao longo do tempo, além de permitir uma comparação entre diferentes cursos hídricos ou entre diferentes pontos de um mesmo curso. A 
utilização de índices de qualidade de água tem como objetivo a simplificação de uma série de parâmetros em valores inteiros.

Além desta medida, pode ser aplicado de forma simultânea ouso deuma classificação prévia seguindo as diretrizes do instrumento de enquadramento do corpo hídrico, conforme estabelecido na Política Nacional de Recursos Hídricos, Lei 9433/1997 (BRASIL, 1997), onde o enquadramento dos corpos hídricos em classes, segundo os usos preponderantes da água, visa estabelecer metas de qualidade compatível para os corpos de água com os usos mais exigentes a que forem destinadas, a fim de assegurar os usos preponderantes estabelecidos, possibilitando compatibilizar os usos múltiplos dos recursos hídricos superficiais, de acordo com a qualidade pretendida para os mesmos, e diminuir os custos de combate a poluição das águas, mediante ações preventivas permanentes, auxiliando no planejamento ambiental de bacias hidrográficas e no uso sustentável dos recursos naturais. A partir do enquadramento de um corpo hídrico, os parâmetros de qualidade da água e as restrições dos usos preponderantes são definidos para sua respectiva classe, devendo ser seguidos para garantir a compatibilidade entre o uso e a qualidade disponível, consequentemente a harmonia sócioambiental e o equilíbrio ecológico do ambiente.

De acordo com Oliveira, Souza e Castro (2009), apesar de sua importância sócio-econômica, a bacia hidrográfica do rio Apodi-Mossoró vem sofrendo constantes impactos derivados de atividades antrópicas, que acabam constituindo-se em fonte de contaminação e ameaça ao ambiente e a saúde, sendo estas ações provenientes da lixiviação de defensivos agrícolas das diversas atividades desenvolvidas no entorno do rio; carreamento de material alóctone; além das constantes descargas de esgotos domésticos e industriais lançados em toda a extensão da bacia. Assim, é de extrema importância o conhecimento da qualidade de suas águas superficiais, de forma a planejar o gerenciamento adequado deste recurso, avaliando impactos e prevenindo sua degradação.
Nesse contexto, o presente trabalho tem como objetivo avaliar o corpo hídrico do rio ApodiMossoró nos barramentos hidráulicos situados no trecho urbano em Mossoró-RN, com base na metodologia do IQA, seguindo os padrões estabelecidos pela CETESB. Além de verificar as condições do corpo hídrico aplicando uma classificação prévia conforme as diretrizes do instrumento de enquadramento, posteriormente com base na classe, avaliar individualmente os parâmetros do IQA comparando com a legislação ambiental vigente e elencar as principais atividades contribuintes com as alterações químicas, físicas e biológicas na área em estudo.

\section{Material e Métodos}

A bacia hidrográfica do rio Apodi-Mossoró, localizada na região oeste do estado do Rio Grande do Norte, apresenta uma área de $14.276 \mathrm{~km}^{2}$, equivalente a $26,8 \%$ da área do estado, representa a maior bacia hidrográfica potiguar (RIO GRANDE DO NORTE, 2012). Seu rio principal (ApodiMossoró) possui $210 \mathrm{~km}$ de extensão, com a nascente entre o Rio Grande do Norte e a Paraíba, em São Brás, no município de Luis Gomes e foz no Oceano Atlântico, onde abriga uma planície litorânea, na forma de estuário, entre os municípios de Areia Branca e Grossos, ver Figura 1.

Sendo que a área de estudo, caracteriza-se climaticamente inserida em região semi-árida, apresentando temperatura média anual de $28,5^{\circ} \mathrm{C}$ e precipitação média anual $400 \mathrm{~mm}$, concentrada, principalmente no período de março a abril.

Segundo o CPRM (2005), o município de Mossoró situa-se na mesorregião Oeste Potiguar e na microrregião Mossoró, limitando-se com os municípios de Tibau, Grossos, Areia Branca, Serra do Mel, Açu, Upanema, Governador Dix-Sept Rosado, Baraúna e o Estado do Ceará, abrangendo uma área de $2.100 \mathrm{~km}^{2}$. A sede do município tem uma altitude média de $16 \mathrm{~m}$ e apresenta coordenadas $05^{\circ} 11^{\prime} 16,8^{\prime \prime}$ de latitude sul e $37^{\circ} 20^{\prime} 38,4^{\prime \prime}$ de 
longitude oeste. O município encontra-se totalmente inserido nos domínios da bacia hidrográfica Apodi-Mossoró, sendo banhado pela sub-bacia do Rio Mossoró, observa-se na Figura 2 que o rio corre pela cidade no sentido sudoeste-nordeste, apresentando-se sinuoso nessa região e com vários açudes e lagos nas proximidades de suas margens.
Sua várzea apresenta larguras apreciáveis, da ordem de 500 a 1000 m, estreitando-se junto ao Centro, onde existem três pontes que fazem a ligação entre a parte mais antiga da Cidade, na margem esquerda do rio, e o Bairro Alto de São Manoel, que se desenvolveu mais recentemente na margem direita do rio (ARAÚJO; SANTOS; ARAÚJO, 2007).

Figura 1. Mapa de localização do Brasil, região Nordeste, estado do Rio Grande do Norte, bacia hidrográfica do Apodi-Mossoró e município de Mossoró.

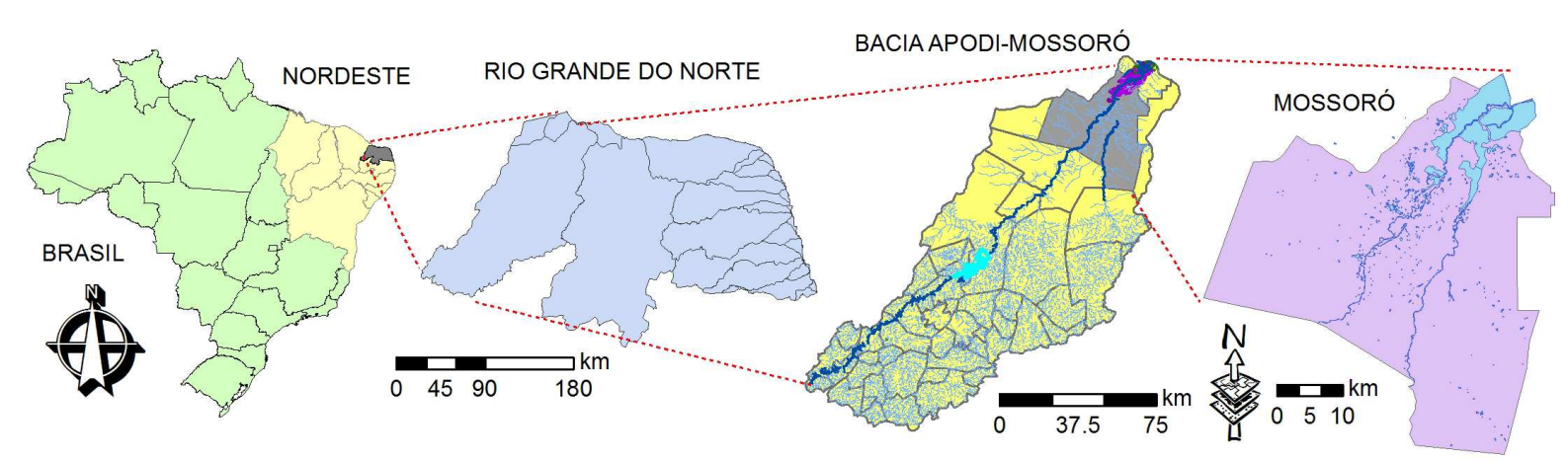

Fonte: Elaboração dos autores.

Foi avaliada a situação ambiental de um ecossistema com o uso de indicadores estabelecidos no IQA recomendado por Bonnet, Ferreira e Lobo (2008): potencial hidrogeniônico $(\mathrm{pH})$, turbidez, nitrogênio total, fósforo total, temperatura, coliformes termotolerantes, oxigênio dissolvido (OD), sólidos totais e demanda bioquímica de oxigênio (DBO). Os valores obtidos foram utilizados no cálculo do IQA, e forneceram a medida da magnitude de desequilíbrio no sistema, podendo ser indicada numa amplitude de 0 a 100 , a qual qualifica a água desde péssima a excelente passando pelas faixas ruim, aceitável e boa.

Foi também avaliado o comportamento espacial dos indicadores, através do georreferenciamento dos locais de amostragem, subsidiando indicar os pontos críticos. A coleta das amostras pontuais de água superficial e dos demais dados foram realizadas em três barramentos hidráulicos, conforme apresentado na Tabela 1 e Figura 2.

Tabela 1. Coordenadas georreferenciadas dos três pontos de coleta.

\begin{tabular}{cccc}
\hline Ponto & Barragem do Genésio (B1) & Barragem do centro (B2) & Barragem das Barrocas (B2) \\
\hline X Coordenadas $\mathrm{mE}$ & 681464 & 683867 & 685184 \\
Y Coordenadas $\mathrm{mN}$ & 9422890 & 9425546 & 9427518 \\
\hline
\end{tabular}

Nota: Coordena dos locais de coletas, georreferenciadas com aparelho GPS Garmin Quest, Projeção UTM, Datum SAD 69, Zona $24 \mathrm{~S}$.

Fonte: Elaboração dos autores. 
Figura 2. Localização da área urbana do município de Mossoró e dos barramentos hidráulicos amostrados.

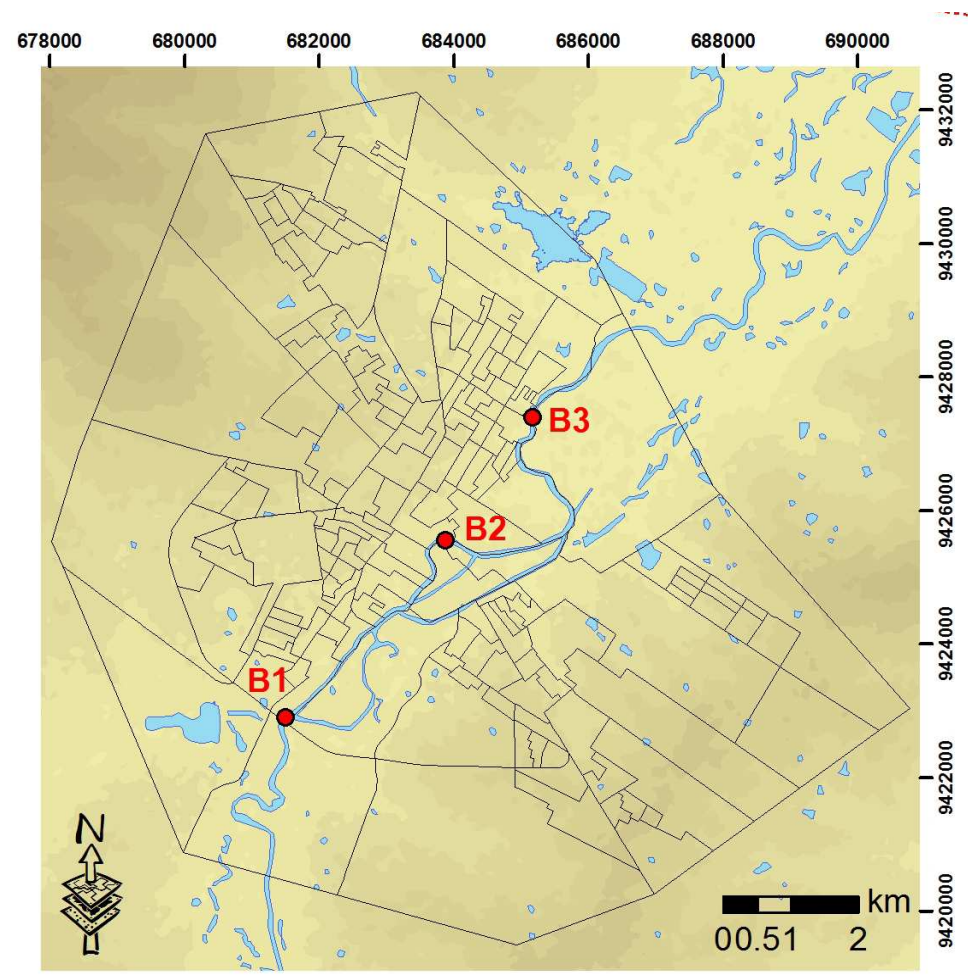

Fonte: Elaboração dos autores.

As amostragens foram realizadas a montante da parede dos barramentos hidráulicos, reduzindo os fatores de oxigenação, sendo a água encontrada a montante praticamente estagnada fator que estabiliza a presença e as concentrações dos elementos. Sendo as coletas realizadas no dia 22 de maio de 2010. A Figura 3 apresenta a caracterização do regime pluviométrico do primeiro semestre do ano de 2010, na área em estudo, onde constata-se a ausência de eventos de precipitação no devido mês.
Para a classificação prévia da condição em que o corpo d'água se encontrava foram obedecidas a resolução CONAMA n 357/2005 (BRASIL, 2005) e resolução CNRH no 91/2008 (BRASIL, 2008), que instituem as diretrizes para os procedimentos metodológicos de enquadramento dos corpos hídricos, sendo necessário realizar análise do parâmetro referente a salinidade da água e elencar os usos múltiplos, entre eles os mais preponderantes e exigentes em padrões de captação para potabilidade. 
Figura 3. Distribuição diária do regime de precipitação pluvial $(\mathrm{mm})$, temperatura média do $\operatorname{ar}\left({ }^{\circ} \mathrm{C}\right)$ e radiação solar $\left(\mathrm{MJ} \mathrm{m}^{-2}\right)$, no período de janeiro a junho de 2010.

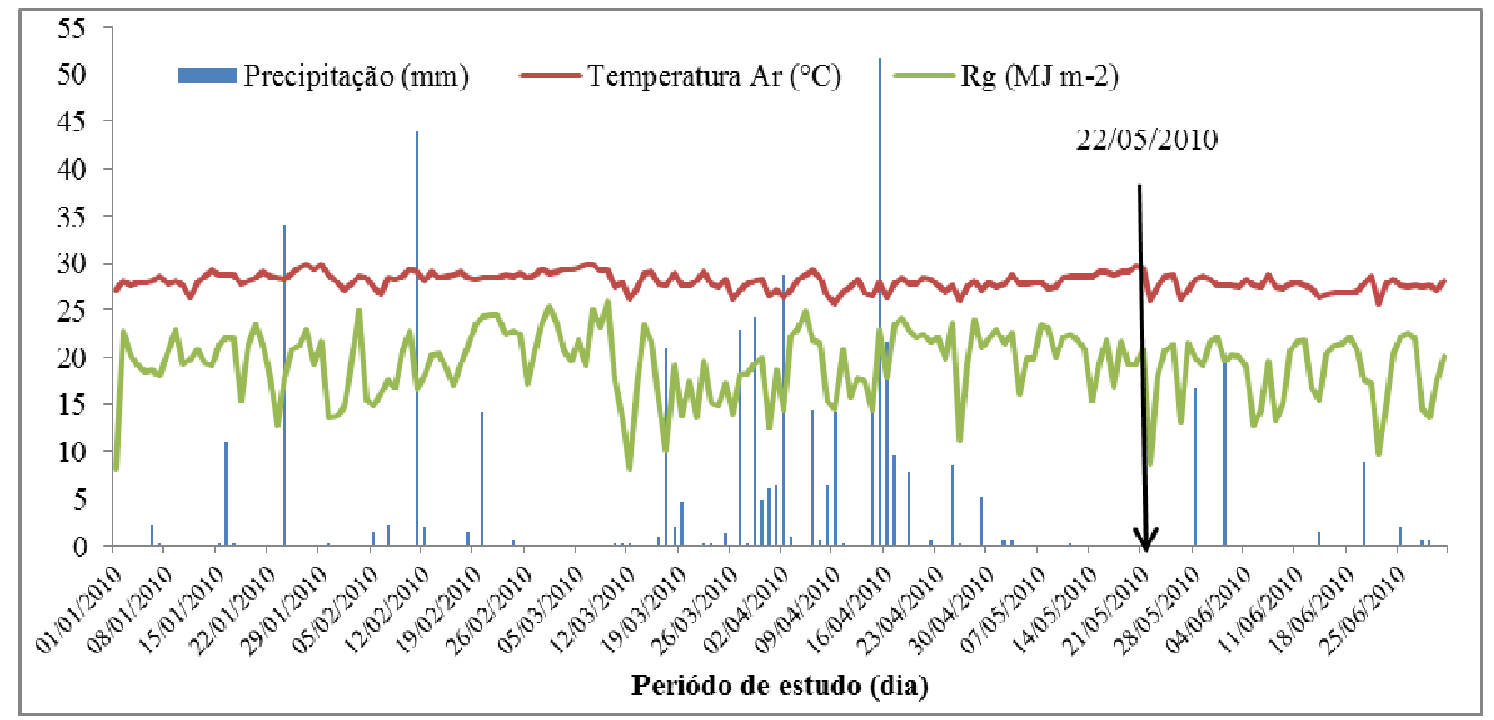

Fonte: Elaboração dos autores.

Para caracterizar os principais usos da água do rio Apodi-Mossoró no trecho do município de Mossoró-RN, foram realizados levantamentos de dados in loco, onde as visitas ao local ocorreram de maio a julho de 2010, período com condições climáticas uniformes (escassez de precipitações), aliado a revisões bibliográficas de relatórios técnicos e pesquisas que envolveram a área de estudo.

Para as leituras das concentrações de condutividade elétrica (CE), potencial hidrogeniônico $(\mathrm{pH})$ e oxigênio dissolvido (OD), foi utilizado aparelho portátil com suas respectivas sondas, para obtenção da determinação analítica in loco. Enquanto as análises dos parâmetros restantes, tais como: turbidez, temperatura, $\mathrm{DBO}$, nitrogênio total, fósforo total e resíduo total ou sólido total (ST), foram realizados no Laboratório de Diagnóstico Físico-Químico da Universidade Estadual do Rio Grande do Norte (UERN) campus Mossoró-RN, sendo as análises realizadas de acordo com as normas previstas no Standarth Methods for the examination of water and wastewater (APHA et al., 2005). As análises microbiológicas foram realizadas no Laboratório de Inspeção de Produtos de Origem Animal (UFERSA), compreendendo apenas a identificação e quantificação do nível populacional de coliformes termotolerantes $(\mathrm{CF})$.

Por fim sendo realizada a avaliação individual qualitativa e quantitativa dos valores obtidos nas análises de água referentes aos parâmetros do IQA comparados com os padrões prescritos na resolução CONAMA n 357/2005 (BRASIL, 2005).

O Índice de estado trófico para potencial de eutrofização foi calculado conforme a classificação do estado trófico com base apenas no fósforo, para rios segundo Von Sperling (2011).

\section{Resultados e Discussão}

Com os valores das análises obtidas expostos na Tabela 2, verificou-se que a qualidade das águas do corpo hídrico do rio Apodi-Mossoró, está comprometida pelas atividades antrópicas. A partir da entrada da cidade e à jusante desta, em função da grande carga de efluentes domésticos e agroindustriais, lançadas pelos empreendimentos e residências alocadas nas proximidades do corpo hídrico, além da contribuição do lançamento de 
esgoto clandestino nos canais de drenagem de águas pluviais, aliado ao despejo e lixiviação de defensivos agrícolas que usam fertilizantes químicos em áreas adjacentes a cidade, desta forma de acordo com a classificação da CETESB (SÃO PAULO, 2008) a água apresenta-se com qualidade boa no primeiro barramento e regular nos segundo e terceiro barramentos.

Tabela 2. Resumo das análises físico-químicas e biológicas, para avaliação do índice de qualidade de água (IQA) das amostras de água superficiais do rio Apodi-Mossoró no trecho urbano em Mossoró/RN.

\begin{tabular}{lcccc}
\hline Parâmetros & B1 (Genésio) & B2 (Centro) & B3 (Barrocas) & VLP \\
\hline Turbidez $(\mathrm{NTU})$ & 30,3 & 100,1 & 21,0 & - \\
Fósforo $\left(\mathrm{mg} \mathrm{L}^{-1}\right)$ & 0,18 & 2,93 & 6,21 & $<0,12$ \\
Nitrogênio $\left(\mathrm{mg} \mathrm{L}^{-1}\right)$ & 1,95 & 7,76 & 12,46 & - \\
Resíduo sólido total $\left(\mathrm{mg} \mathrm{L}^{-1}\right)$ & 1320,0 & 1392,0 & 1514,0 & - \\
$\mathrm{pH}$ & 7,9 & 8,3 & 7,8 & 6,5 a 8,5 \\
Oxigênio dissolvido $\left(\mathrm{m} \mathrm{L}^{-1}\right)$ & 8,4 & 7,9 & 5,0 & $\geq 5,0$ \\
Temperatura $\left({ }^{\circ} \mathrm{C}\right)$ & 29,0 & 31,0 & 29,0 & - \\
Coliformes termotolerantes (NMP/100 $\mathrm{mL})$ & $<3$ & 36 & $<3$ & $<50^{1}$ \\
DBO $\left(\mathrm{mg} \mathrm{L}^{-1}\right)$ & 7,90 & 15,80 & 9,30 & - \\
Índice de Qualidade da Água (IQA) & 73,81 & 45,14 & 51,91 & - \\
Classificação do IQA & BOA & REGULAR & REGULAR & - \\
\hline
\end{tabular}

Nota: DBO - Demanda Bioquímica de Oxigênio e pH - potencial Hidrogeniônico. VLP - Valores Limites Permitidos para águas salobras classe 1, segundo Resolução CONAMA n ${ }^{0}$ 357/2005 (BRASIL, 2005). ${ }^{1}$ - Valor Limite Permitido de acordo com a resolução CONAMA n 274/2000 (BRASIL, 2000), estabelecendo categoria muito boa.

Fonte: Elaboração dos autores.

Além da presença das atividades antropogênicas nas áreas de mata ciliar do rio, ocorre a presença de sinuosidade do eixo da calha do rio e a tricotomização de alguns trechos em estudo (Figura 2), o que contribui aos processos de erosão marginal e assoreamento, aliados ao baixo fluxo de vazão e elevado potencial de sedimentação, proveniente dos taludes sem proteção de mata ciliar. Esta situação acarreta o incremento das cargas de sólidos trazidos pelo deflúvio superficial, causando elevação da turbidez da água.

Estabelecendo comparação com os IQA's obtidos por Araújo, Santos e Araújo (2007) no município de Mossoró no período de janeiro de 2007, verificouse que as classes obtidas para os barramentos do Genésio e do Centro foram aceitável $(62,81)$ e ruim $(43,49)$, respectivamente. Corroborando com a interferência promovida pelas ações antropogênicas e os efeitos da sazonalidade climática.
Em relação aos valores das análises físico químicas o OD apresentou valores semelhantes aos obtidos por Araújo, Santos e Araújo (2007), sendo o maior valor na barragem do Genésio, enquadrandose na condição de eutrofização. Já o excesso das concentrações de fosforo ocorreram na barragem das barrocas, estando situada mais a jusante, recebendo contribuições mistas de origem rural pelas atividades agrícolas nas margens do rio, e urbanas pelo lançamento irregular de efluentes in natura, via um canal de drenagem pluvial, contribuindo diretamente no processo de eutrofização.

Em geral, o corpo hídrico do rio ApodiMossoró em Mossoró-RN, apresenta qualidade preocupante visto que o fósforo junto ao nitrogênio, está associado a floração de algas indesejáveis, a diminuição na vegetação aquática submersa, comprometendo os usos múltiplos previstos para os empreendimentos e atividades que venham captar 
tais recursos, provavelmente onerando o tratamento de acordo com as necessidades.

Portanto, apesar do rio Apodi-Mossoró receber uma vazão de regularização do reservatório de Santa Cruz, situado no município de Apodi-RN, as águas do rio Apodi-Mossoró no trecho considerado, são de caráter salobras, apresentando salinidades oscilando, conforme apresentado na Tabela 3, fato este corroborado pela presença de águas estagnadas a jusante dos barramentos, represando as vazões dos trechos retidos, desta forma sofrendo influência do clima semi-árido, pelos elevados regimes de temperatura do ar, radiação solar e acentuada evaporação.

Tabela 3. Resultados da condutividade elétrica (CE), obtidas nos barramentos do rio Apodi-Mossoró em MossoróRN.

\begin{tabular}{cccc}
\hline Barramento & Resultado quantitativo $\left(\mathbf{d S ~}^{\mathbf{- 1}}\right)$ & Salinidade $(\mathbf{p p m})$ & Resultado qualitativo \\
\hline B1 & 1,991 & 1274,24 & SALOBRA \\
B2 & 1,950 & 1248,00 & SALOBRA \\
B3 & 1,840 & 1177,60 & SALOBRA \\
\hline
\end{tabular}

Nota: B1 - barramento do Genésio; B2 - barramento do Centro e B3 - barramento Barrocas.

Fonte: Elaboração dos autores.

Uma possível hipótese levantada para tais concentrações diz respeito à sazonalidade local, visto que o registro das concentrações ocorreu no período em que o fluxo natural do rio (ambiente lótico) estava baixo, assemelhando-se a um ambiente lêntico, devido à baixa vazão, e estiagem dos eventos de precipitação, associado à presença de sólidos suspensos pelos deflúvios superficiais dos taludes expostos e as atividades de dragagem da areia do fundo.

Segundo a resolução CONAMA no 357/2005 (BRASIL, 2005) e os usos preponderantes da água verificados no rio Apodi-Mossoró (recreação, pesca, dessedentação de animais, irrigação, extração de areia por maquinários de dragas, lançamento de esgoto doméstico e industrial, despejos de resíduos sólidos, deságue das calhas de drenagem de água pluvial, ocupação das áreas de preservação permanente desmatadas por habitações e pequenos comércios, além de pequenas agroindústrias e industriais que contribuem com o lançamento de águas residuárias in natura percebe-se que as águas deste são utilizadas como águas salobras de Classe 1, entretanto, as condições da qualidade de água não satisfazem aos padrões estabelecidos na resolução
CONAMA n ${ }^{\circ} 357 / 2005$ para esta classe, conforme apresentado na Tabela 2.

Quando se verifica os parâmetros, analisados individualmente e comparados aos padrões estabelecidos pela resolução CONAMA $n^{\circ}$ $357 / 2005$, pode ser averiguado que a turbidez, resíduos sólidos e temperatura não existem menção na mesma, enquanto os demais estão dentro dos limites exigidos, exceto o fósforo total, onde este no período de estiagem de 2010 apresentou em todos os barramentos, os níveis acima do limite estabelecido pela resolução CONAMA no 357/2005 que estabelece o valor de referência de $0,12 \mathrm{mg}$ $\mathrm{L}^{-1}$. O nitrogênio total não é padrão de referência da resolução CONAMA no $357 / 2005$, entretanto o nitrogênio amoniacal não foi caracterizado por análise.

Este resultado é preocupante visto que o fósforo junto ao nitrogênio está associado ao crescimento excessivo de algas, floração de algas indesejáveis, e a uma diminuição na vegetação aquática submersa (NEFF et al., 2000).

Constata-se na Tabela 2 a ocorrência de baixos valores de coliformes termotolerantes em uma 
região que recebe a contribuição pelo lançamento de esgotos sem tratamento na calha do rio, tal fato é justificado pelo poder de autodepuração do rio, associado a presença do indicio de eutrofização elevando o consumo de OD, corroborado pela sinuosidade, consequente oxigenação do mesmo, além da presença de resíduos agroindustriais que corroboram no processo de decomposição, associado a atividades de dragagem no canal, além da elevada insolação, acentuado fotoperíodo e elevados registros de radiação solar, que auxiliam no controle natural dos patógenos.

Segundo a classificação do índice de estado trófico (VON SPERLING, 2011) o potencial de eutrofização dos barramentos hidráulicos do rio Apodi-Mossoró no trecho em estudo é considerado como Ultraolígotrófico, pois apresenta concentração de fósforo total inferior a $5 \mathrm{mg} \mathrm{m}^{-3}$. Entretanto, chama-se atenção a presença de atividades que usam defensivos agrícolas, situadas em áreas de mata ciliar, além da ocorrência do lançamento de águas residuária e esgotos domésticos, estes com incremento pontual de produtos de limpeza (substâncias surfactantes), as quais, em longo prazo, podem comprometer a qualidade do corpo hídrico e seus respectivos usos múltiplos.

Ressalta-se que o controle dessas concentrações abaixo dos limites previstos é ferramenta ímpar para se evitar os efeitos degradantes do processo de eutrofização, como a depleção de oxigênio, diminuição da diversidade biológica e aumento da população de algas e macrófitas (TUNDISI, 2003).

As consequências da eutrofização artificial nas comunidades aquáticas são intensas e os prejuízos sócio-econômicos deste processo são inúmeros, a começar pela perda da qualidade da água, com provável impedimento de seu uso para o abastecimento, turismo e lazer, sem contar ainda com o perigo das florações tóxicas de cianobactérias.

De acordo com Araújo et al. (2012), a Tabela 4, corrobora com os eventos observados in loco, elencando e enumerando as fontes possíveis de degradação do rio Apodi-Mossoró no trecho em estudo, dentro do sítio urbano de Mossoró (entre os barramentos B1 e B3), em que as atividades degradadoras situam-se dentro da Área de Preservação Permanente do rio.

Tabela 4. Quantitativo das fontes de poluição na Área de Preservação Permanente do rio Apodi/Mossoró.

\begin{tabular}{ccc}
\hline Fontes de Poluição & Quantidade (pontual) & $\mathbf{( \% )}$ \\
\hline Esgoto & 14 & 36,8 \\
Atividade Agrícola & 5 & 13,2 \\
Criação de Animais & 7 & 18,4 \\
Lixo nas margens & 4 & 10,5 \\
Olaria & 2 & 5,3 \\
Extração de Areia & 6 & 15,8 \\
TOTAL & 38 & 100 \\
\hline
\end{tabular}

Fonte: Araújo et al. (2012).

Portanto, a principal causa de poluição do rio é o esgoto doméstico, lançado sem qualquer tratamento (in natura), contribuindo para elevação da DBO, fósforo e nitrogênio da água. Entretanto, a falta de saneamento básico e as ligações clandestinas são os grandes responsáveis por esse cenário.
Partindo do princípio que a violação de apenas um parâmetro é suficiente para que o curso d'água não possa ser enquadrado em classes de maior qualidade, faz-se necessário, a intervenção do Poder público para tomar medidas e ações no sentindo de que o rio Apodi-Mossoró passe a ser definido como 
de água salobra e classificado como Classe 1 e que apresente a qualidade requerida da classe da qual seus usos múltiplos necessitam.

Portanto, a adoção de medidas mitigadoras e compensatórias, aliadas a conscientização ambiental são de extrema importância para compatibilizar os usos existentes com a qualidade da água do rio, em beneficio da saúde da população local e redução dos investimentos para implantação de soluções técnicas que visem a contenção dos problemas de poluição ambiental.

\section{Conclusões}

A sazonalidade climática exerce influência sobre as concentrações das variáveis consideradas, e a contaminação tende a aumentar no sentido montante-jusante da cidade, sendo verificado que a água apresenta-se com qualidade boa no primeiro barramento e regular nos demais.

Os padrões de qualidade de água contemplam as diretrizes das legislações ambientais vigentes, com exceção dos padrões de fosforo, os quais chamam atenção por serem indicadores do processo de eutrofização.

As ações antrópicas principalmente as atividades situadas no trecho urbano e a jusante deste são conflitantes entre si e contribuem para a poluição do rio Apodi-Mossoró, sendo elencadas as principais atividades impactantes do corpo hídrico o lançamento de efluentes in natura no canal pluvial de drenagem, as atividades agrícola e de criação de animais, ambas situadas nas margens do rio.

É de grande importância salientar que a qualidade da água com suas características físico-químicas e bacteriológicas é essencialmente dependente das condições do próprio meio em que se encontra, sendo indicadora da situação de equilíbrio ou degradação de todo um ecossistema. Desta forma, espera-se que os resultados obtidos ao longo deste estudo, possam contribuir fornecendo subsídios para o desenvolvimento de um planejamento ordenado, auxiliando a preservação de forma sustentável desta microbacia e dos recursos naturais desta região, além de subsidiar a adoção de políticas públicas de monitoramento e a implementação do enquadramento do corpo hídrico.

\section{Agradecimentos}

À Universidade Federal Rural do Semi-Árido (UFERSA) e a Prefeitura Municipal de Mossoró pelo apoio e fomento à pesquisa. Ao professor Rafael Oliveira pelo auxílio nos trabalhos de campo.

\section{Referências}

ABRAHÃO, R. Impactos do lançamento de efluentes na qualidade da água do riacho Mussuré. 2006. Dissertação (Mestrado em Desenvolvimento e Meio Ambiente) Universidade Federal da Paraíba, João Pessoa.

AMERICAN PUBLIC HEALTH ASSOCIATION APHA; AMERICAN WATER WORKS ASSOCIATION - AWWA; WATER ENVIRONMENT FEDERATION WPCR. Standard methods for the examination of water and wastewater. 21. ed. Washington: APHA, AWWA, WPCR, 2005. $1268 \mathrm{p}$.

ARAÚJO, D. N.; SILVA, P. C. M.; DIAS, N. S.; LIRA, D. L. C. Estudo da área de preservação permanente do rio Mossoró no sítio urbano de Mossoró-RN por meio de técnicas de Geoprocessamento. Revista Caatinga, Mossoró, v. 25, n. 2, p. 177-183, mar./jun. 2012.

ARAÚJO, V. S.; SANTOS, J. P.; ARAÚJO, A. L. C. Monitoramento das águas do Rio Mossoró/RN, no período de abril/2005 a julho/2006. Holos, Natal, v. 1, n. 23, p. 4-41. 2007.

ATHAYDE JÚNIOR, G. B.; NÓBREGA, C. C.; GADELHA, C. L. M.; SANTANA, N. C. B.; COSTA, M. D. Principais usos da água do rio Sanhauá na área de influência do antigo lixão do Roger: proposta de revisão de enquadramento do rio. Revista Ambiente \& Água - An Interdisciplinary Journal of Applied Science, Taubaté, v. 3, n. 3, p. 128-142. 2008.

BONNET, B. R. P.; FERREIRA, L. G.; LOBO, F. C. Relações entre qualidade da água e uso do solo em Goiás: uma análise à escala da bacia hidrográfica. Revista Árvore, Viçosa, v. 32, n. 2, p. 311-322, 2008. 
BRASIL. Lei Federal nº 6.938, de 31 de agosto de 1981. Dispõe sobre a Política Nacional do Meio Ambiente, seus fins e mecanismos de formulação e aplicação, e dá outras providências. Diário Oficial [da] República Federativa do Brasil, Brasília, 02 set. 1981. seção 1, p. 16.509. Disponível em: $<$ http://www.cnrh.gov.br>. Acesso em: 29 maio 2013.

Lei Federal $n^{0}$ 9.433/97 de 08 de janeiro de 1997. Institui a política Nacional de Recursos Hídricos, cria o Sistema Nacional de Gerenciamento de Recursos hídricos, regulamenta o inciso XIX do art. 21 da Lei $\mathrm{n}^{\circ}$ 8.001, de 13 de março de 1990, que modificou a Lei $\mathrm{n}^{\circ}$ 7.990, de 28 de dezembro de 1989. Diário Oficial [da] República Federativa do Brasil, Brasília, 09 jan. 1997. seção 1, p. 470. Disponível em: <http://www.cnrh.gov. br>. Acesso em: 29 maio 2013.

Resolução CNRH no 91, de 05 de novembro de 2008. Dispõe sobre procedimentos gerais para enquadramento dos corpos de água superficiais e subterrâneos. Diário Oficial [da] República Federativa do Brasil, Brasília, 06 fev. 2009. seção 1, p. 99. Disponível em: <http://www.cnrh.gov.br>. Acesso em: 29 maio 2013.

. Resolução CONAMA n ${ }^{\circ} 274$, de 29 de novembro de 2000. Define os critérios de balneabilidade em águas brasileiras. Diário Oficial [da] República Federativa do Brasil, Brasília, 25 jan. 2001. seção 1, p. 70-71. Disponível em: <http://www.cnrh.gov.br $>$. Acesso em: 29 maio 2013.

. Resolução CONAMA n ${ }^{\circ} 357$, de 17 de março de 2005. Dispõe sobre a classificação dos corpos de água e diretrizes ambientais para o seu enquadramento, bem como estabelece as condições e padrões de lançamento de efluentes. Diário Oficial [da] República Federativa do Brasil, Brasília, 18 mar. 2005. seção 1, p. 58-63. Disponível em: <http://www.cnrh.gov.br>. Acesso em: 29 maio 2013.

GOMES, M. A.; LANI, J. L.; COSTA, L. M.; PONTES, L. M.; FIGUEREDO, N. A.; BARDALES, N. G. Solos, manejo e aspectos hidrológicos na bacia hidrográfica do Araújos, Viçosa- MG. Revista Árvore, Viçosa, v. 36, n. 1, p. 93-102, 2012.

NEFF, R.; CHANG, H.; KNIGHT, C. G.; NAJJAR, R. G.; YARNAL, B.; WALKER, H. A. Impact of climate variation and change on mid-Atlantic Region hydrology and water resources. Climate Research, London, v. 14, n. 3, p. 207-218. 2000.
OLIVEIRA, D. G.; FERREIRA, R. A.; MELLO, A. A.; OLIVEIRA, R. S. C.; OLIVEIRA, R. S. C. Análise da vegetação em nascentes da bacia hidrográfica do Rio Piauitinga, Salgado, SE. Revista Árvore, Viçosa, v. 36, n. 1, p. 127-141, 2012.

OLIVEIRA, T. M. B. F.; SOUZA, L. D.; CASTRO, S. S. L. Dinâmica da série nitrogenada nas águas da bacia hidrográfica Apodi/Mossoró - RN - Brasil. Eclética Química, São Paulo, v. 34, n. 3, p. 17-26, 2009. Disponível em: <http://www.scielo.br/eq>. Acesso em: 23 jul. 2010.

RIO GRANDE DO NORTE. Secretaria de meio ambiente e recursos hídricos. 2012. Mossoró, Brasil. Disponível em: <http://www.semarh.rn.gov.br>. Acesso em: 29 maio 2012.

SÃO PAULO. Companhia de tecnologia de saneamento ambiental. Qualidade das águas interiores no estado de São Paulo. Significado ambiental e sanitário das variáveis de qualidade das águas e dos sedimentos e metodologias analíticas e de amostragem. Série relatórios. Apêndice A. Governo do Estado de São Paulo: Secretaria do Meio Ambiente, 2008. 40 p.

SILVA, A. P. S.; DIAS, H. C. T.; BASTOS, R. K. X.; SILVA, E. Qualidade da água do reservatório da usina hidrelétrica (UHE) de Peti, Minas Gerais. Revista Árvore, Viçosa, v. 33, n. 6, p. 1063-1069, 2009.

SERVIÇO GEOLÓGICO DO BRASIL - CPRM. Diagnóstico do município de Mossoró. Projeto cadastro de fontes de abastecimento por água subterrânea Rio Grande do Norte. Mossoró, 2005. Disponível em: $<\mathrm{http}$ // www.cprm.gov.br>. Acesso em: 29 maio 2013.

TUNDISI, J. G. Água no século XXI enfrentando a escassez. São Carlos: RiMa - Instituto Internacional de Ecologia, 2003. 247 p.

UMETSU, R. K.; PEREIRA, N.; CAMPOS, E. M. F. P.; UMETSU, C. A.; MENDONÇA, R. A. M.; BERNASCONI, P.; CAMARGO, M. F. Análise morfométrica e socioambiental de uma bacia hidrográfica amazônica, Carlinda, MT. Revista Árvore, Viçosa, v. 36, n. 1, p. 83-92, 2012.

VON SPERLING, M. Introdução à qualidade das águas e ao tratamento de esgotos. 4. ed. Belo Horizonte: DESA/ UFMG, 2011. 452 p. (Princípios do tratamento biológico de águas residuárias, v. 1). 
